isolated from peripheral blood by negative selection, cultured with TLR9 ligand, CpG oligodeoxynucleotide, and with B cell activating factor of TNF family (BAFF), then the citrullinated peptide specific antibody production was measured on day 7.

Results 5-mer and 19-mer citrullinated filaggrin peptides were recognised by the RA sera, with a sensitivity and specificity that was comparable with the currently used tests. RA sera specifically recognised the C terminally, and not by the $\mathrm{N}$-terminally biotinylated 5 -mer peptide, while did not differentiate between $\mathrm{C}$ and $\mathrm{N}$ terminally biotinylated 19 -mer peptide, suggesting that the $\mathrm{N}$-terminal amino acids in the 5 -mer peptide are crucial for recognition. The data obtained with both the 5-mer and the19-mer peptides showed significant correlation with the anti-CCP titers of commercial test.

To see whether B cells from RA patients and normal individuals produce citrullinated peptide specific antibodies in vitro, purified B cells were stimulated via TLR9 by CpG in the presence of BAFF. B cells from RA patients synthesised a substantial amount of antibodies that specifically recognised the 5 -mer citrullinated filaggrin peptide, while B cells from normal blood donors did not, indicating that autoreactive $B$ cells that are specific for citrullinated proteins can be stimulated via TLR9 to produce anticitrullinated peptide antibodies. Such mechanism may contribute to the pathogenicity of ACPA.

Conclusion The five-mer citrullinated filaggrin peptide as a well defined short epitope could be important for development of new diagnostic tools for RA, and also may facilitate to reveal phenotypic and functional differences of autoreactive and normal B cells.

\section{A150 SHORT CITRULLINATED EPITOPE OF FILAGGRIN IS RECOGNISED BY SERA AS WELL AS ANTIBODIES PRODUCED IN VITRO BY B CELLS OF RHEUMATOID ARTHRITIS PATIENTS}

Eszter Szarka, ${ }^{1}$ Monika Adori, ${ }^{1}$ Fruzsina Babos, ${ }^{2}$ Anna Magyar, ${ }^{2}$ Ferenc Hudecz, ${ }^{2}$ György Nagy, ${ }^{3}$ Judit Pozsgay, ${ }^{1}$ Gabriella Sármay ${ }^{1,4}{ }^{1}$ Department of Immunology, Eötvös Loránd University, Budapest, Hungary; ${ }^{2}$ HAS-ELTE Research Group of Peptide Chemistry, Budapest, Hungary; ${ }^{3}$ Buda Hospital of Hospitaller Brothers of St. John, Budapest, Hungary; ${ }^{4}$ Immunology Research Group of the Hungarian Academy of Sciences at the Eötvös Loránd University, Budapest, Hungary

\subsection{6/ard.2010.149005.17}

Background and objectives Autoantibodies in about $70 \%$ of rheumatoid arthritis (RA) patients recognising citrullinated proteins (ACPA) are cross-reactive with citrullinated filaggrin epitopes. Although filaggrin is an epithelial protein and is not expressed in synovial tissues, so is probably not the in vivo target of ACPA, sysnthetic peptid epitopes of filaggrin are good tools for the early diagnosis of RA. Our main goals are to identify the optimal citrullinated epitope(s) applicable in highly sensitive diagnostic tests and also recognised by ACPA producing $B$ cells, thus allowing phenotyping and functional studies of this population.

Materials and methods The previously identified citrullinated epitopes were synthesised by SPPS, according to Fmoc/ tBu strategy, biotinylated at either the C-or the N-terminal end respectively, and tested for their reactivity with sera of RA and other autoimmune patients by ELISA. B cells were 